\title{
Operational Risk for Funds of Hedge Funds - An Analysis of Regulatory Requirements Under Dodd-Frank Act
}

\author{
Ohaness Paskelian \\ University of Houston Downtown
}

\author{
Stephen Bell \\ Park University - Parkville Campus \\ Julia Creek \\ Park University - Parkville Campus
}

\begin{abstract}
As a result of the 2008 financial crisis, there was an overwhelming regulatory response both in the U.S. and worldwide designed to prevent the financial and regulatory shortcomings that led to the crisis. Among the many provisions passed into law, the new legislation imposes regulations on hedge funds pertaining to new registration and reporting requirements, risk rules, and investment limits. In this paper, we overview of the new regulatory requirements that were enacted based on the Dodd-Frank Act of 2010. The requirements apply to both hedge funds and fund of hedge funds operations. In particular, we will study the regulations which directly influence operational due diligence for both U.S.-based fund of hedge funds and non-U.S.-based fund of hedge funds interacting with U.S. markets.
\end{abstract}

Keywords: hedge funds, fund of hedge funds, Dodd-Frank Act

\section{INTRODUCTION}

Unlike a hedge fund, which invests primarily in different types of individual securities, fund of hedge funds (FoHFs hereinafter) is company that makes investments in other hedge funds. Investors seeking diversification can do so by investing in FoHFs, which provide a different return/risk profile than other investment instruments. FoHFs also provide investor access to some of the most highly skilled investment managers in the world. Without FoHFs, smaller investors would be denied access to hedge fund manager sophistication due to prohibitive account minimums or other barriers to small investor access.

In addition, FoHFs provide investors with professional sourcing, due diligence, and monitoring. Funds of hedge funds represent themselves as companies that have experienced professionals operating within well-structured due diligence processes designed to provide ongoing monitoring functions. However, the FoHF sector's due diligence competence became the subject of intense media and legislative criticism when it was discovered that several European FoHFs had invested heavily in the fraudulent Madoff ponzi scheme. A very legitimate question was repeatedly raised, how could a supposedly sophisticated financial sector 
(FoHFs) fail to detect (and thus avoid) the commitment of millions of investor client dollars into a fraudulent scheme? (Amin and Kat, 2002).

The 2008 financial crisis took a heavy toll on FoHFs. Beginning in mid-2008, investors withdrew investment funds from FoHFs for 21 consecutive months. Many FoHFs did not survive and were forced to shut down. Most of the largest FoHFs suffered significant damage but managed to stay afloat through the crisis (Agnew, 2010).

The 2008 financial crisis resulted in substantial new legislation in the U.S. and worldwide. The new regulations were designed to prevent the same financial problems that beset the FoHF prior to and during the crisis. In particular, the new legislation imposes regulations on hedge funds pertaining to new registration and reporting requirements, risk rules, and investment limits.

In this paper, we provide an exploratory analysis of the new regulatory requirements that FoHFs will be facing as they go forward in the marketplace. In particular, we will study the regulations which directly influence operational due diligence for both U.S.-based FoHFs and non-U.S.-based FoHFs interacting with U.S. markets.

\section{OVERVIEW OF OPERATIONAL RISKS IN FOHFS}

Operational risks arise from the very operations of FoHFs. The FoHFs operating environment combines the areas of trade registration and processing, accounting functions, administrative functions, security analysis and valuation, and reporting. In 2003, Capco reported the results of a survey related to hedge funds operations and found that operational issues were the leading cause of hedge fund failure. The survey pinpointed identifiable operational issues as the direct cause of failure among $54 \%$ of failed hedge funds. Separately, Capco identified operational risk as the cause of failure for more than half of all failed hedge funds. Since FoHFs invest directly in hedge funds, they would inherently have similar operational risk characteristics.

Capco's survey was instrumental in discovering some of the important causes of hedge fund failures. Misrepresentation of investment characteristics, misappropriation of investors investments, trading without investor consent, deviation from fund investment style and inadequate resources were found to be the most common operational problems that contributed to the hedge fund failures. Misrepresentation of investment characteristics which entails falsifying or exaggerating investments valuation and projections is considered one of the most serious and troublesome causes of failures of hedge funds. Another serious problem is the misappropriation of funds which involve using investment funds for personal and non-investment related purposes by the hedge fund managers. According to the survey, the most common reason for misappropriation is to cover other trading losses in the hedge fund. Unauthorized trading involves making investments without investor approval, or making investments outside of investor approved range of products. Style breach happens when the hedge fund chooses to deviate from the fund's main advertised investment style. Finally, inadequate resources can represent a number of different hedge fund operational deficiencies, such as lack of state of the art technology, highly trained personnel, and other operational processes which result in FoHF failure to handle operating volumes or investment activities. (Brown et al., 2004)

A more comprehensive due diligence and monitoring methodology should be designed to eliminate the above-referenced operational problems. Conducting operational due diligence efforts is challenging in that a FoHF takes only a partial view of firm operations in a very limited period of time. The process is further complicated by the wide range of disciplines which the FoHF must examine in order to develop a snapshot of firm operations. The FoHF must examine the areas of risk management, financing, clearing, and settlement in order to complete its work. Therefore, the due diligence process must contain a clear and detailed mechanism in controlling all aspects of the operational risk. Capco's survey (2003) provides detailed and comprehensive operational due diligence processes that can be used by FoHFs. An operational due diligence process should provide an overview of the organizational structure of the FoHF, detailing its structure, assessing the quality of personnel, and examining the technology and the data quality used in making the fund's investment decisions. The objective of the operational due diligence system is to cover 
both internal and external processes and systems and information flows. In addition, the due diligence system should overview the operational characteristics of different external partners such as prime brokers, custodians and other administrators. Obviously, one due diligence process cannot fit the needs of all FoHFs, since each FoHF has unique characteristics and differing investment strategies. Therefore, any valid due diligence process should be tailored to take into consideration FoHFs objectives and investment style (Brown, Fraser and Liang, 2008).

Due diligence should be an integral part of the operations of any FoHF. Capco's survey (2003) notes that the bulk of due diligence is performed during the early stages of the investment process at a time when investments are being made in different securities. However, the truly efficient and effective due diligent process should be permanent and cover the overall operations of the FoHF, well beyond the time of initial allocation of funds into investments.

\section{CURRENT REGULATORY ENVIRONMENT FOR FoHFS}

In order for due diligence methodologies to be effective, Congress enacted new regulations designed to strengthen and improve both SEC and state financial regulatory agencies. A key element of the legislation was to broaden the definition of the term "investment adviser" which in turn required significantly more financial institutions to be subject to SEC registration. Under the new investment adviser definition, FoFHs are recognized as investment advisers and have the obligation to register with the SEC. This new regulation will mean much greater SEC scrutiny for the FoFH industry, particularly when its effect is combined with new recordkeeping, reporting, and examination requirements. To further strengthen the regulatory oversight of SEC, investment advisers with SEC are required to have record-keeping and report-filing functions as part of SEC new regulations. Those new regulations were enacted in order to achieve the goals of protecting the public and/or investors or to assist the Financial Stability Oversight Council in evaluating systemic risk. Further, the new regulations require that the SEC perform periodic verification and review of the records of SEC-registered private funds to achieve the above-referenced SEC goals. When taken as a whole, it is clear that the new regulations are aimed at improving the ability of FoHFs to engage in meaningful due diligence. (Brown et al., 2008)

The Dodd-Frank Act of 2010 provided fundamental and overnight changes to regulatory environment of the American financial services industry. Among the most significant changes was the elimination of exempting "private advisers" from SEC registration. The definition of an "investment adviser" is rather broad. Any person who does any type of advising activity directly or indirectly, through paid client relationships or through unpaid writings on public or private outlets on matters related to investment decisions or security valuations falls under the category of investment advisers.

The Dodd-Frank Act also enhanced SEC regulatory power by requiring all types of advisers including advisers to "private funds" to register with the SEC. Prior to Dodd-Frank, private equity fund and most hedge fund advisers were exempt from SEC registration because they claimed to have fewer than 15 clients. Advisers to "private funds" fall into the category of advisers with no affiliation to a public investment company or business development company. Also, those advisors are not publicly recognized to provide investment advising services to clients over the period of last 12 months. Dodd-Frank eliminates this exemption and thus requires SEC registration for those entities falling under the definition. (Brown et al., 2009; U.S. Congress 2010)

\section{New Exemptions}

However, The Dodd-Frank Act has added some new provisions which require the SEC to grant an exemption from SEC registration for certain categories of investment advisers. The reader should note that the provisions only exempt affected investment adviser entities, however, those same entities are still subject to other SEC antifraud regulations under the Advisers Act. Of particular interest to FoHF managers is the new exemption for investment advisers that act only in their capacity as advisors to private FoHFs and they have assets under management in the U.S. valued to less than $\$ 150$ million. The key to compliance with this new regulation is understanding the distinction between managing private funds versus managing 
a relatively small number of accounts for individual clients. For example, estate planning vehicles such as trusts may not be considered a "fund" but instead an individual account thus triggering the SEC registration requirement. Likewise, funds held in limited liability corporations rather than individual client accounts may be interpreted to be a "fund" thus exempting the adviser from registration. As one can see, the form of the investment vehicle and whether it is considered a "fund" under the meaning of the registration provision is critical to determining whether private advisers, including FoHF advisers, are required to undergo SEC registration. (U.S. Congress 2010).

\section{Foreign Private Advisers}

A "foreign private adviser" falls under the category of investment advisors without a U.S. business domiciliation. However, if the "foreign advisor" has less than 15 clients in the U.S. in an advisory relationship OR if the advisers fall into the category of advisers having no affiliation to a public investment company or business development company provided that the U.S. clients under the advisory relationship have $\$ 25,000,000$ or less invested in private funds, then such foreign advisers are exempt from SEC registration under the Dodd-Frank Act. Of course those not meeting the exemption requirements would still have to register with the SEC in the U.S. as an investment adviser.

\section{Commodity Trading Advisors That Advise Private FoHFs}

Commodity Trading Advisors (CTAs) enjoy certain exemptions from SEC registration under both the Advisers Act and the Dodd-Frank Act. Under the Advisers Act, a CTA can claim exemption from SEC registration if it is already registered with CFTC and the business operations have no affiliation to a public investment company or business development company. Similarly, the Dodd-Frank Act provides exemptions to CTAs registered with the CFTC, however, if the adviser's business changes to primarily providing investment related advice, then the Dodd-Frank Acts stipulates that the adviser registers with the SEC. (Brown et al., 2008).

\section{Venture Capital FoHF Advisers}

The Dodd-Frank Act provided investment advisers who specialize in advising venture capital FoHFs clients with exemption from SEC registrations. Such advisers will have separate SEC reporting and recordkeeping requirements.

A "venture capital FoHF" is a FoHF that primarily adopts a venture capital strategy and advertises itself to clients as such. Furthermore, the investments made by a venture capital FoHF are either qualifying investment or short-term investment; up to $20 \%$ of investors deposited assets can be used to acquire other types of investments. Qualifying investment is equity in companies acquired by the FoHF, while short-term investment consists of cash, cash equivalents and U.S. Treasuries with 60 days of maturity or less. A venture capital FoHF cannot use leverage in excess of $15 \%$ of total capital contributions of investors. In addition, any type of leverage should have maturities no longer than 120 days. The FoHF will be a registered investment company under the Investment Company Act, and will issue only shares that buy, withdraw or redeem into the FoHF, without providing the holder with any additional rights.

Before Dodd-Frank Act, SEC regulations required registration of investment advisers if their assets under management exceeded $\$ 30$ million. SEC registration was not required if assets under management fell under \$25 million. Advisers with assets under management between \$25 million and \$30 million had the option to either register with the SEC or the state in which they maintained their principal business operations. After Dodd-Frank became law, the SEC categorizes small investment advisers as those having less than \$25 million assets under management. Those investment advisers falling into the "small" category are not allowed to register with the SEC and are regulated at the state level where they adopt their primary place of business. The SEC categorizes mid-sized investment advisers as those entities with assets under management between $\$ 25$ million and \$100 million. As with the "small" category, mid-sized investment advisers are regulated at the state level. (Girard, 2004; Stromqvist, 2009). 


\section{RECORD KEEPING AND REPORTING}

Investment advisors working for FoHFs have the responsibility to keep records and file reports as deem required by the SEC. The SEC can base this requirement on either of two criteria. First, maintaining records and filing reports can be required for transparency and protection of the public interest and investor assets. Also, record keeping and report filing provide information to the Financial Stability Oversight Council for the purpose of assessing systemic risk. The Dodd-Frank Act stipulates that in case the SEC requires an investment adviser to provide records and reports, then the adviser must provide documentation related to several key aspects of FoHF operations including the amount of assets under management, leverage usage, the amount of trading activity and current positions held, counterparty credit risk exposure, valuation methodologies and approaches adopted by the FoHF, the types of assets held, and other information which the SEC in consultation with the Financial Stability Oversight Council deems consistent with the abovereferenced requirements. (Brown, Gregoriou \& Pascalau, 2012).

\section{EXAMINATION}

Prior to the enactment of Dodd-Frank, investment adviser inspections were conducted by the SEC when circumstances gave rise to concerns about higher levels of risk. This meant that SEC inspections were sometimes infrequent for FoHFs managed by SEC-registered investment advisers. The Dodd-Frank Act requires that the SEC conduct regularly scheduled inspections of such FoHF's records. This is a radical departure from past SEC practices and should greatly improve the ability of the SEC to make early systemic risk assessments which should improve the ability of the agency to head off financial crises similar to one experienced in 2008. (Cagan, 2007).

\section{CONCLUSIONS}

The greatest challenge for the FoHF investment manager is the assessment and management of operational risk. In order to maximize FoHF performance, it is imperative that the investment manager implement the operational risk checks involving separation of duties, clear reporting practices, strategies for interacting with regulators, following through on promises made to clients and making proper disclosure to clients.

Operational risk is deeply embedded in FoHF operational frameworks. Furthermore, since operational risk management involves personnel with expertise in a wide variety of domains, FoHFs should develop and cultivate the right personnel into groups designed to conduct operational due diligence utilizing state of the art methods which will both improve performance and prevent future financial industry crises. The new SEC registration, recordkeeping/reporting, and examination regulations referenced in this paper represent significant strides toward industry-wide improvement in these areas. FoHFs can become an excellent investment product in the category of alternative assets primarily geared toward institutional investors transparency and operational due diligence can be demonstrated.

\section{REFERENCES}

Agnew, H. (2010). Funds of hedge funds withstand Financial Hurricane. Financial New. Retrieved from http://www.efinancialnews.com/story/2010-07-19/funds-of-hedge-funds-withstand-financialhurricane

Amin, G., \& Kat, H.M. (2002). Portfolio of Hedge Funds: What Investors Really Invest In. Working Paper. Retrieved from http://papers.ssrn.com/sol3/papers.cfm?abstract id=296642

Brown, S.J., Fraser, T.L., \& Liang, B. (2008). Hedge Fund Due Diligence: A Source of Alpha in a Diversified Hedge Fund Strategy. Journal of Investment Management, 6, 23-33.

Brown, S.J., Goetzmann, W.N., \& Liang, B. (2004). Fees on Fees in Funds of Funds. Journal of Investment Management, 2, 39-56. 
Brown, S.J., Goetzmann, W.N., Liang, B., \& Schwarz, C. (2008). Mandatory Disclosure and Operational Risk: Evidence from Hedge Fund Registration. Journal of Finance, 63, 2785-815.

Brown, S.J., Goetzmann, W.N., Liang, B., \& Schwarz, C. (2009). Estimating Operational Risk for Hedge Funds: The $\omega$-Score. Financial Analysts Journal, 65, 43-53.

Brown, S.J., Gregoriou, G.N., \& Pascalau, R. (2012). Diversification in Funds of Hedge Funds: Is it Possible to Overdiversify? The Review of Asset Pricing Studies, 2(1), 89-110.

Cagan, P. (2007). Operational risk red flags: Lessons learned from ten hedge fund blow-ups. Journal of Securities Operations and Custody, 1(2), 131-152.

Capco. (2003). Understanding and Mitigating operational risk in Hedge Fund Investments. A Capco White Paper, The Capital Markets Company Ltd.

Girard, J.R. (2004). The management of Hedge Funds' Operational Risks. Working paper, EDHEC Risk and Asset Management Research Center, France.

Stromqvist, M. (2009). Hedge funds and financial crises. Economic Review, 1, 87-106.

U.S. Congress. (2010). The Dodd-Frank Act of 2010. Retrieved from http://www.sec.gov/about/laws/wallstreetreform-cpa.pdf 